\title{
Adoção da Modelagem Matemática: o que se mostra na literatura produzida no âmbito da Educação Matemática
}

\author{
Adoption of Mathematical Modelling: what is seen in the research \\ produced by the Mathematical Education community
}

\author{
Gabriele de Sousa Lins Mutti* \\ ORCID iD 0000-0002-6347-7207 \\ Tiago Emanuel Klüber* \\ ORCID iD 0000-0003-0971-6016
}

\begin{abstract}
Resumo
Repercute das pesquisas produzidas pela comunidade da Educação Matemática um discurso de incentivo voltado à adoção da Modelagem na escola. Embora esse discurso seja reconhecido, faz-se necessário trazer à clareza o que a comunidade busca expressar quando se refere à essa adoção. Assim, assumindo a atitude fenomenológica de investigação interrogamos: o que se mostra sobre a adoção da Modelagem Matemática na literatura produzida no âmbito da Educação Matemática? Essa interrogação levou-nos a considerar 109 pesquisas dirigidas à Modelagem, disponibilizadas no Catálogo de Dissertações de Teses da Comissão de Aperfeiçoamento de Pessoal de Nível Superior, no Google Acadêmico e na Biblioteca Digital Brasileira de Teses e Dissertações. A análise delas revelou que recorrentes menções à adoção da Modelagem restringem-se aos aspectos favoráveis, desafios e procedimentos necessários ao trabalho com ela na escola, não havendo iniciativas que busquem entender a adoção focando aquele que é o sujeito passível de adotá-la, o professor.
\end{abstract}

Palavras-chave: Adoção. Modelagem Matemática. Produções Acadêmicas. Perspectiva Fenomenológica. Professor.

\begin{abstract}
An incentive discourse aimed at adopting Modeling at school affects the research produced by the Mathematics Education Community. Although this discourse is recognized, it is necessary to clarify what the community seeks to express when referring to this adoption. Thus, assuming the phenomenological attitude of research, we ask: what is seen on the adoption of Mathematical Modeling in the literature produced within the scope of Mathematics Education? This interrogation led us to consider 109 researches directed to Modeling, made available in the Catalog of Theses Dissertations of the Commission for the Improvement of Higher Education Personnel, in Google Academic and in the Brazilian Digital Library of Theses and Dissertations. Their analysis revealed that recurrent mentions to the adoption of Modeling are restricted to the favorable aspects, challenges, and procedures necessary to work with it at school, with no initiatives seeking to understand the adoption by focusing on who is the subject able to adopt it, the teacher.
\end{abstract}

\footnotetext{
" Doutora em Educação em Ciências e Educação Matemática, Universidade Estadual do Oeste do Paraná (UNIOESTE). Professora da Secretaria Estadual de Educação do Paraná (SEED-PR), Foz do Iguaçu, Paraná, Brasil.E-mail: gabi_mutti@ hotmail.com.

** Doutor em Educação Científica e tecnológica, Universidade Federal de Santa Catarina (UFSC). Professor da Universidade Estadual do Oeste do Paraná (UNIOESTE), Cascavel, Paraná, Brasil. E-mail: tiago_kluber@yahoo.com.br.
} 
Keywords: Adoption. Mathematical Modelling. Academic Productions. Phenomenological Perspective. Teacher. 1 Introdução

A ampliação da relevância atribuída à Modelagem Matemática ${ }^{1}$ na perspectiva da Educação Matemática, tanto no âmbito das discussões voltadas à Didática da Matemática quanto em meio à comunidade escolar, foi destacada por Kaiser (2005). Investigações mais recentes, como as desenvolvidas por Bonotto (2017), Forner (2018) e Campos (2018), acabam por reiterar essa ampliação ao tomarem a Modelagem como objeto de estudo, discutindo-a sob aspectos como a formação de professores, o currículo escolar e a divisão do trabalho entre estudantes durante desenvolvimento de atividades de Modelagem.

Além das pesquisas que buscam interrogar a Modelagem sob diferentes aspectos, argumentos favoráveis a ela são encontrados em documentos como as Diretrizes Curriculares da Educação Básica do Paraná (PARANÁ, 2008), as Diretrizes para a Formação de Professores (BRASIL, 2015) e a Base Nacional Comum Curricular (BRASIL, 2018). Dentre esses argumentos, está a possibilidade de instigar o interesse dos estudantes pela Matemática por meio de atividades cujos problemas geradores advém de temáticas que lhes são familiares (ou sobre as quais manifestam curiosidade) e que podem, inclusive, estar relacionadas a outras áreas do conhecimento (KLÜBER; BURAK, 2007; ALMEIDA; SILVA; VERTUAN, 2012).

Outro fator que pode contribuir com o trabalho com a Modelagem na escola é o favorecimento da constituição de espaços nos quais o modelo de prática pedagógica assumido pelo professor tende a distanciar-se do habitual, pautado na escassez de diálogo e na reprodução sequencial de conteúdo, segundo indicação dos currículos escolares linearmente concebidos (ROSA; OREY, 2012; KLÜBER, 2016).

Autores como Silveira (2007), Geiger (2011) e Ceolim (2015), por outro lado, chamam a atenção em suas pesquisas para o que entendem como obstáculos que se interpõem ao trabalho com a Modelagem na escola. Esses obstáculos vão do apego dos professores àquelas práticas pedagógicas próximas ao paradigma do exercício² (SKOVSMOSE, 2000), ao sentimento de despreparo no que concerne ao como inserir e conduzir atividades de Modelagem em contextos escolares nos quais está instaurada uma cultura pedagógica avessa à essa tendência ${ }^{3}$.

\footnotetext{
${ }^{1}$ Adotaremos as expressões Modelagem Matemática e Modelagem como sinônimos.

${ }^{2}$ No qual há apresentação oral de conteúdos e a reprodução de listas de exercícios pautados no livro didático (SKOVSMOSE, 2000).

3 "Tendência é entendida neste trabalho como um movimento efetivo daquilo que tem permanecido enquanto e como alguns modos de se pensar e fazer Educação Matemática em nosso país e, também em outras partes do mundo" (KLÜBER, 2012, p. 33).
} 
Ainda que sejam discutidos os obstáculos que se interpõem ao trabalho com a Modelagem, eles não impedem que ecoe fortemente da literatura um discurso de incentivo voltado a sua $a d o c ̧ \tilde{a} o^{4}$ na sala de aula (CARVALHO, 2011; TAMBARUSSI, 2015; MUTTI; KLÜBER, 2018).

Esse discurso é evidenciado pela fala de Carvalho (2011, p. 96, grifo nosso) quando diz que “[...] pesquisadores da área da Educação Matemática têm apontado a Modelagem Matemática como metodologia/método/estratégia/tendência a ser adotada na sala de aula", bem como pela fala de Luna (2012, p. 87, grifo nosso) ao dizer "[...] que os estudos de Doerr e English (2006), Antonius et al. (2007) e Leib (2005) mostram a relevância da adoção da Modelagem por professores da Educação Básica".

Ao lermos essas citações e dedicarmo-nos, de modo mais profundo, ao estudo da literatura produzida pela comunidade da Educação Matemática, demo-nos conta de que a expressão adoção da Modelagem e suas conjugações ${ }^{5}$ têm sido, ao longo dos anos, recorrentemente mencionadas por pesquisadores da área, o que nos permite considerá-la no âmbito das discussões instauradas nas pesquisas publicadas. As citações extraídas de parte dessas pesquisas, corroboram com essa asserção:

\begin{tabular}{|l|l|}
\hline \multicolumn{1}{|c|}{ Citação } & \multicolumn{1}{c|}{ Autor } \\
\hline $\begin{array}{l}\text { "Critérios norteadores para a adoção da Modelagem Matemática no ensino de } 1^{\circ} \text { e } \\
2^{\circ} \text { graus" }\end{array}$ & $\begin{array}{l}\text { Burak (1992, p. 290, } \\
\text { grifos nossos) }\end{array}$ \\
\hline $\begin{array}{l}\text { "Enfatizo a consonância, ou seja, que a adoção da Modelagem deve ser acompanhada } \\
\text { do movimento do currículo em direção a uma perspectiva de investigação, nomeada } \\
\text { por Skovsmose (2000) de cenários de investigação" }\end{array}$ & $\begin{array}{l}\text { Barbosa (2001, p. 38, } \\
\text { grifos nossos) }\end{array}$ \\
\hline $\begin{array}{l}\text { "Salientamos, entretanto, que a estratégia de modelagem pode ser adotada em } \text { em } \\
\text { qualquer situação ou ambiente educacional" }\end{array}$ & $\begin{array}{l}\text { Bassanezi (2012, p. 11, } \\
\text { grifos nossos) }\end{array}$ \\
\hline $\begin{array}{l}\text { "Large-scale assessment that tests facts and procedures through multiple choice } \\
\text { questions also hinders the adoption of modelling" }\end{array}$ & $\begin{array}{l}\text { Caron e Muller (2004, } \\
\text { p. 74, grifos nossos) }\end{array}$ \\
\hline $\begin{array}{l}\text { "Os principais pontos negativos explicitados pelos professores cursistas para } \\
\text { justificar a não adoção da Modelagem Matemática nas suas práticas de sala de aula" }\end{array}$ & $\begin{array}{l}\text { Silveira (2007, p. 100, } \\
\text { grifos nossos) }\end{array}$ \\
\hline $\begin{array}{l}\text { "The adoption of mathematical modeling and solving realistic problems, and natural } \\
\text { issues research is an essential component of the math curriculum and conduct an an } \\
\text { intensive training courses for mathematics teachers to renew their knowledge" }\end{array}$ & $\begin{array}{l}\text { Mrayyan (2016, p. 121, } \\
\text { grifos nossos) }\end{array}$ \\
\hline
\end{tabular}

Quadro 1 - Menção a adoção da Modelagem em pesquisas nacionais e internacionais Fonte: Os autores (2020)

Conforme considerávamos as citações apresentadas e ampliávamos nossas leituras, dirigindo atenção para artigos, dissertações, teses e capítulos de livros cujas temáticas voltavam-se à Modelagem, víamos emergir, repetidas vezes, menções à sua adoção. Essas menções, ao mesmo tempo que pareciam testemunhar a relevância da adoção da Modelagem

\footnotetext{
4 Ainda que o dicionário Houaiss (2019, p. 1$)$, defina adoção como “[...] aceitação, admissão do que antes era externo, alheio, estranho ou não era conhecido", quando interrogamos o que diz a comunidade Educação Matemática sobre a adoção, estamos atentos a outras possíveis compreensões que possam emergir dos dizeres dos autores, quando a mencionam e/ou a discutem em suas pesquisas.

${ }_{5}^{5}$ Adotar, adotam ou mesmo adotando.
} 
no contexto da comunidade da Educação Matemática, encerravam em nós uma inquietação de modo que passamos a interrogar: o que se mostra sobre a adoção da Modelagem na literatura produzida no âmbito da Educação Matemática?

Essa interrogação de pesquisa, assumida na perspectiva fenomenológica, mostrou-se norteadora dessa investigação e sua pertinência revela-se em dois aspectos. O primeiro é o próprio movimento da comunidade acadêmica e escolar, destacado por Burak (2016, p. 38, grifo nosso), quando diz que “[...] a crescente adoção dessa forma de ensinar matemática é percebida na formação de grupos de trabalho, em revistas de divulgação da Educação Matemática e na realização de eventos específicos regionais e nacionais relativos à Modelagem Matemática".

Por mais que o movimento dos grupos de trabalho, das revistas e dos eventos da área ${ }^{6}$ evidencie a ampliação de inciativas dirigidas à adoção da Modelagem e, além dele, ecoe da literatura no âmbito da Educação Matemática e de documentos oficiais, um discurso de incentivo voltado à essa adoção, é notória a ausência ${ }^{7}$ de pesquisas que tomem a adoção da Modelagem como fenômeno ${ }^{8}$ (ou objeto ${ }^{9}$ ) de estudo ou que empreendam sobre ela discussões que visem compreendê-la em seu profundo sentido ${ }^{10}$, condição que se mostra como segundo aspecto que reitera a pertinência dessa investigação.

Tomando os aspectos supracitados como evidências de um campo de pesquisa ainda em aberto, empenhamo-nos em explicitar o que expressa a comunidade da Educação Matemática sobre a adoção da Modelagem Matemática. Para tanto, organizamos esse artigo de modo que no próximo subtítulo diremos da trajetória de pesquisa na qual nos envolvemos ao buscar pela

\footnotetext{
${ }^{6}$ Dentre os eventos da área destacam-se em âmbito nacional e internacional, a Conferência Nacional sobre Modelagem na Educação Matemática (CNMEM), o Simpósio Internacional de pesquisa em Educação Matemática (SIPEM) e o Encontro Nacional de Educação Matemática (ENEM). Mencionamos esses eventos, de modo particular, por estarem entre os mais citados no âmbito das 109 pesquisas analisadas nesse artigo. Ressaltamos, entretanto, a relevância do International Conference on Teaching Mathematical Modelling and Applications (ICTMA) e do International Congress on Mathematical Education (ICME) como espaços internacionais de discussão e divulgação de pesquisas voltadas à Modelagem Matemática.

${ }^{7}$ Essa ausência é demonstrada quando olhamos para as dissertações e teses brasileiras dirigidas a Modelagem e publicadas nos últimos 30 anos. Ainda que a expressão "adoção da Modelagem" ou uma de suas conjugações, esteja presente em 55 delas (41 dissertações e 14 teses) nenhuma a toma como foco de investigação.

${ }^{8}$ Quando dizemos fenômeno referimo-nos "ao que se mostra no ato de intuição efetuado por um sujeito individualmente contextualizado, que olha em direção ao que se mostra de modo atento e que percebe isso que se mostra nas modalidades pelas quais se dá a ver no próprio solo em que se destaca como figura de um fundo" (BICUDO, 2011, p. 30).

9 Esclarecemos que dizemos "ou objeto", pois este "é um termo que quando não é utilizado em sentido fenomenológico, frequentemente se refere ao objeto em si, puro, dado, fora do campo perceptivo ou mesmo da intencionalidade. Utilizar o termo em sentido fenomenológico não significa desconsiderar essa posição, mas assumir que não é possível afirmar nada sobre esse objeto fora do campo da intencionalidade" (KLÜBER, 2012, p. 52).

10 "Sentido é aquilo em que se sustenta a compreensibilidade de alguma coisa [...] aquilo que pode articular-se na abertura compreensiva [...] questionar sobre o sentido do ser [envolve perguntar] sobre ele mesmo na medida em que ele se dá dentro da compreensibilidade da presença” (HEIDEGGER, 2015, p. 213, inserção nossa).
} 
produção e a análise dos dados. Na sequência, explicitaremos o que se mostra sobre a adoção da Modelagem quando, num movimento fenomenológico-hermenêutico de investigação, tomamos como região de inquérito as pesquisas dirigidas à Modelagem produzidas pela comunidade da Educação Matemática nos últimos 30 anos.

\section{Sobre a produção e análise dos dados}

Quando assumimos a pesquisa numa perspectiva fenomenológica, nos propomos a explicitar o que se mostra sobre o fenômeno interrogado, a saber, a adoção da Modelagem Matemática nas pesquisas produzidos no âmbito da Educação Matemática, cônscios de que conhecê-lo em sua essência ${ }^{11}$ envolve não the impor “[...] aquisições e visões prévias [tampouco] noções populares, [mas] assegurar seu tema científico mediante [...] as coisas mesmas" (HEIDEGGER, 2015, p. 153, inserções nossas). Este fazer atento e rigoroso envolve buscar, nos discursos dos sujeitos significativos ${ }^{12}$, no nosso caso os autores das pesquisas consideradas, “[...] perspectivas que se doem a compreensão" (PAULO; AMARAL; SANTIAGO, 2010, p. 74).

O movimento de procura por essas perspectivas foi iluminado pela interrogação de pesquisa: o que se mostra sobre a adoção da Modelagem na literatura produzida no âmbito da Educação Matemática? Ao demorarmo-nos nela, no intuito de compreender o que buscávamos interrogar, fomos remetidos às pesquisas voltadas à Modelagem Matemática produzidas pela comunidade da Educação Matemática e disponibilizadas no Catálogo de Dissertações e Teses da Comissão de Aperfeiçoamento de Pessoal de Nível Superior (CAPES), no Google Acadêmico, na Biblioteca Digital Brasileira de Teses e Dissertações e nas referências bibliográficas dos trabalhos que encontrávamos.

Ao realizarmos o levantamento das pesquisas dirigidas à Modelagem, não o limitamos a períodos ou autores específicos, apenas optamos pelas que estavam disponíveis em Língua Portuguesa, Inglesa ou Espanhola, em função de nossa maior proximidade com esses idiomas. Durante essa busca, utilizamos as expressões: adoção + Modelagem Matemática, adoção da Modelagem Matemática, adotar + Modelagem Matemática, adotam + Modelagem Matemática, adoption of mathematical modelling, adoption + Mathematical Modelling e adopción de la

\footnotetext{
${ }^{11}$ Essência é o invariante residual, ou seja, aquilo que persiste do fenômeno que interrogamos após variações imaginárias (MERLEAU-PONTY, 1962).

12 Assim chamados, pois "vivenciam o fenômeno investigado" (BICUDO, 2011, p. 67).
} 


\section{modelación matemática.}

Desse levantamento emergiram 320 pesquisas, das quais 109 se mostram convergentes à interrogação, sendo 8 artigos de evento, 7 trabalhos de conclusão de curso, 33 artigos de periódicos, 1 produto educacional ${ }^{13}, 5$ capítulos de livros, 41 dissertações e 14 teses. No Quadro 2 apresentamos de modo sucinto os tipos, autores e anos das pesquisas levantadas:

\begin{tabular}{|c|c|}
\hline Tipos de Pesquisa & Documentos primários ${ }^{14} /$ autores/anos \\
\hline Artigos de Eventos & $\begin{array}{l}\text { P103-Caron e Müller (2004), P66-Neto (2010), P31-Gaebler e Veronez (2010), P33- } \\
\text { Souza (2010), P32-Gonçalves e Junior (2011), P34-Gomes e Silva (2013), P30-Klüber, } \\
\text { Mutti, Tambarussi e Martins (2016), P35-Silva, Silva e Rosa (2017) }\end{array}$ \\
\hline $\begin{array}{l}\text { Trabalhos de } \\
\text { Conclusão de curso }\end{array}$ & $\begin{array}{l}\text { P84-Barros (2010), P42-Furtado (2010), P88-Gonçalves (2010), P23-Baraldi, Javaroni, } \\
\text { Finato e Coelho (2011), P83-Matos (2015), P81-Lopes (2016) e Alves (2018). }\end{array}$ \\
\hline $\begin{array}{ll}\text { Artigos } & \text { de } \\
\text { Periódicos } & \end{array}$ & $\begin{array}{l}\text { P43-Burak (1994), P59-Burak e Klüber (2007), P104-Brown (2002), P41-Burak (2004), } \\
\text { P3-Tastsch e Bisognin (2007), P60-Barasuol (2006), P51-Júnior e Espírito Santo (2006), } \\
\text { P57-Sonego e Bisognin (2010), P50-Burak (2010), P54-Beltrão e Igliori (2010), P58- } \\
\text { Furtado (2010), P101-Geiger (2011), P40-Silva, Lobeiro, Macowski e Correa (2012), } \\
\text { P69-Kistemann (2012), P105-Widjaja (2013), P53-Souza e Luna (2014), P68-Li, Pang, } \\
\text { Yu e Cai (2014), P48- -Burak, Vosgerau e Kluber (2015), P67-Grimaldi (2015), P63- } \\
\text { Perez e Paulo (2015), P52-Burak e Martins (2015), P62-Costa (2016), P102-Mrayyan } \\
\text { (2016), P61-Ceolim e Caldeira (2016), P44-Kaczmarek e Burak (2017), P47- Cararo e } \\
\text { Klüber (2017), P56- -Klüber (2017), P46- Martins, Mutti, Carvalho e Klüber (2018), } \\
\text { P49- Bellei e Klüber (2018), P65-Grimaldi, Victer e Rodrigues (2018), P70-Setti e } \\
\text { Vertuan (2018), P45--Mutti e Kluber (2018) e P37-Silva, Lima e Lira (2018). }\end{array}$ \\
\hline Produto educacional & P71-Bastos e Santos (2016) \\
\hline $\begin{array}{l}\text { Prefácio/Capítulos } \\
\text { de livros }\end{array}$ & $\begin{array}{l}\text { P39-Bassanezzi (2012), P36-Rosso (2016), P109-Burak (2016), P11-Soistak (2016) e } \\
\text { P38-Matos e Santos (2018) }\end{array}$ \\
\hline Dissertações & $\begin{array}{l}\text { P108-Gazzetta (1989), P89-Dias (2005), P85-Abdanur (2006), P3-Tatsch (2006), P11- } \\
\text { Soistak (2006), P2-Silveira (2007), P28-Kfouri (2008), P19-Araújo (2008), P29- } \\
\text { Andrade (2008), P14-Sonego (2009), P26-Ferreira, R. (2009), P92-Silva (2009), } \\
\text { Ferreira, M. (2009), P5-Scheller (2009), Ferreira (2010), P16-Abreu (2011), P20- } \\
\text { Schonardie (2011), P87-Carvalho (2011), P94-Souza, (2011), P25-Bueno (2011), P12- } \\
\text { Brites (2012), P91-Kaviatkovski (2012), P93-Santos (2012), P1-Barbosa (2012), P24- } \\
\text { Zukauskas (2012), P88-Cozza (2013), P13-Matté (2013), P18- Freitas (2014), P87- } \\
\text { Carvalho (2015), P4-Tambarussi (2015), P10-Kovalski (2016), P7--Mutti (2016), P27- } \\
\text { Oliveira (2016), P8-Silva (2017), P9-Cararo (2017), P17-Bellei (2018), P21-Komar } \\
\text { (2017), P22-Martins (2016), P23-Matos (2017), P86-Martens (2018) e P95-Teodoro } \\
\text { (2018) }\end{array}$ \\
\hline Teses & $\begin{array}{l}\text { P97-Burak (1992), P96-Barbosa (2001), P74-Beltrão (2009), P73-Quartieri (2012), P98- } \\
\text { Chaves (2012), P106-Klüber (2012), P99-Luna (2012), P100-Rosa (2013), P75-Ceolim } \\
\text { (2015), P77-Bonotto (2017), P76-Campos (2018), P78-Pontes (2018), P79-Forner } \\
\text { (2018) e P107-Silva (2018) }\end{array}$ \\
\hline
\end{tabular}

Quadro 2 - Pesquisas levantadas Fonte: Os autores (2020)

Levantadas as pesquisas, iniciamos a leitura cuidadosa do que os autores de cada uma delas diziam sobre a adoção da Modelagem. Empenhamo-nos nessa leitura, pois entendemos

\footnotetext{
${ }^{13}$ Diz respeito a uma proposta de ensino por meio da Modelagem Matemática na formação inicial de professores, apresentada por Sandro Aparecido Bastos à Universidade Estadual do Centro-Oeste no ano de 2016 como requisito da dissertação.

${ }^{14}$ Os documentos primários são as 109 pesquisas consideradas nesta investigação. Elas foram organizadas como P1, P2, ..., P109, conforme a indicação do quadro 2.
} 
que os dizeres ${ }^{15}$ dos autores estão plenos de significação ${ }^{16}$ (MERLEAU-PONTY, 1962) e, ao passo que são rigorosamente considerados, podem desvelar aspectos do fenômeno interrogado que buscamos compreender.

A busca pelo desvelamento do fenômeno adoção da Modelagem para a comunidade da Educação Matemática, possibilitada pela consideração minuciosa dos discursos dos autores, deu início ao que na fenomenologia chamamos de análise ideográfica, que intenciona evidenciar a "[...] ideologia presente na descrição ingênua ${ }^{17}$ dos sujeitos" (GARNICA, 1997, p. 116). Esse movimento de redução é tal que permite que o fenômeno adoção da Modelagem seja destacado sem que lancemos sobre ele julgamentos que possam de algum modo ofuscá-lo em sua essência.

Tendo em vista a interrogação de pesquisa: o que se mostra sobre a adoção da Modelagem na literatura produzida no âmbito da Educação Matemática? passamos a destacar dos discursos dos autores das pesquisas levantadas, expressos textualmente, excertos tomados como “[...] importantes para abertura da compreensão do que está sendo dito" (SILVA; BICUDO, 2018, p. 165) sobre adoção da Modelagem.

A reescrita desses excertos em linguagem condizente com a área de pesquisa em que estamos inseridos e realizada de modo cauteloso, visando não modificar o sentido do que foi dito pelos autores, deu origem às unidades de significado. Na figura $1^{18}$ apresentamos, como exemplo, a unidade de significado 4:1 que diz respeito à reescrita do primeiro excerto destacado

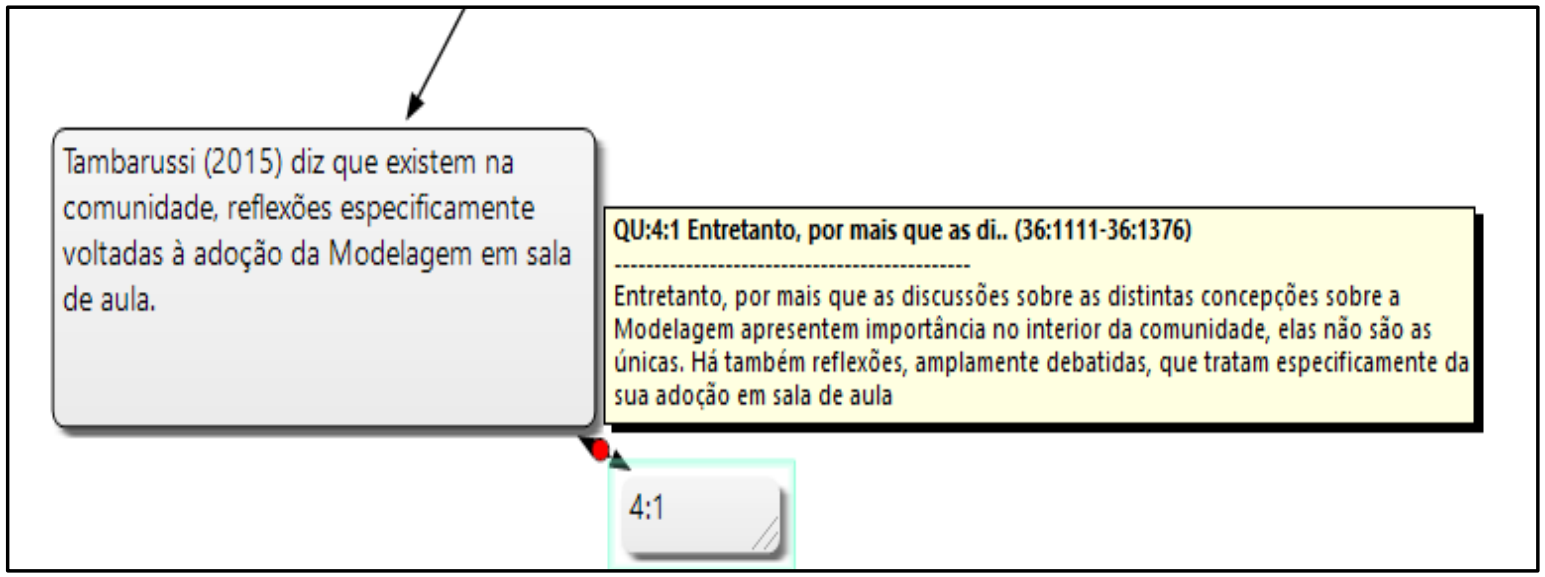

\footnotetext{
${ }^{15}$ Entendemos dizeres como o que se mostra pela palavra manifestada pelos autores das pesquisas levantadas por meio da linguagem textual.

${ }^{16}$ A significação faz a mediação entre a intenção muda do sujeito e a palavra (MERLEAU-PONTY, 1962).

${ }^{17}$ Ressaltamos que tomamos as asserções dos autores das pesquisas levantadas como ingênuas não no sentido de deixarem de atender a critérios de cientificidade e confiabilidade, mas sim no sentido de não ser tematizado, ou seja, mesmo sendo um termo usado pelos autores de artigos científicos, eles não o tematizam, não o tomam como foco de suas reflexões.

${ }^{18} \mathrm{Na}$ Figura 1, o retângulo à esquerda é a unidade de significado 4:1. Esta unidade é a reescrita do primeiro excerto do texto $\mathrm{P} 4$, considerado convergente à interrogação de pesquisa por afirmar haver na comunidade da Educação Matemática, reflexões sobre a adoção da Modelagem na sala de aula. O retângulo à direita, por sua vez, expõe, na íntegra, o excerto destacado tal qual este se apresenta em Tambarussi (2015), página 36, terceiro parágrafo.
} 
no documento primário $\mathrm{P} 4$, relativo à fala de Tambarussi (2015):

Figura 1 - Exemplo de unidade de significado

Fonte: Os autores (2020)

Após a constituição de 371 unidades de significado e a leitura atenta e repetida de cada uma, iniciamos a análise nomotética que compreende o esforço de "[...] transcendência do individual articulada por meio de compreensões abertas pela análise ideográfica, quando devemos atentar às convergências e divergências articuladas nesse momento e avançar em direção ao seguinte, quando perseguimos grandes convergências” (BICUDO, 2011, p. 58-59).

As grandes convergências construídas ${ }^{19}$ entre as unidades de significado levaram-nos a 4 núcleos de ideias, os quais nomeamos: NI1-Aspectos que implicam, advém ou se mostram relevantes para à adoção da Modelagem Matemática, NI2- O professor e a adoção da Modelagem sob distintas perspectivas, NI3-O discurso, critérios norteadores e a produção de materiais visando à adoção da Modelagem e NI4- A adoção da Modelagem mencionada dentre os focos, objetivos e resultados de pesquisa. No Quadro 3 apresentamos uma síntese do que é dito em cada núcleo de ideias:

\begin{tabular}{|c|l|}
\hline Núcleos & \multicolumn{1}{c|}{ Síntese } \\
\hline NI1 & $\begin{array}{l}\text { Diz de aspectos considerados pelos autores das pesquisas levantadas como favoráveis à adoção } \\
\text { da Modelagem. Por outro lado, eles referem-se à existência de questões, como as concepções } \\
\text { prévias dos professores, que implicam nessa decisão, sendo relevante a consideração de } \\
\text { aspectos como a formação de professores para que a adoção da Modelagem aconteça. }\end{array}$ \\
\hline NI2 & $\begin{array}{l}\text { Diz que os professores têm demonstrado disposição em adotar a Modelagem e o fazem a partir } \\
\text { de diferentes concepções de Modelagem defendidas na literatura. }\end{array}$ \\
\hline NI3 & $\begin{array}{l}\text { Expressa a existência, no âmbito da literatura, de um reiterado discurso de incentivo à adoção } \\
\text { da Modelagem. Para além dele, buscam-se por critérios e materiais didáticos que permitam ao } \\
\text { professor compreender como desenvolver a Modelagem na escola. }\end{array}$ \\
\hline NI4 & $\begin{array}{l}\text { Mostra que os autores das pesquisas levantadas têm destacado a adoção da Modelagem como } \\
\text { um aspecto componente dos objetivos de seus estudos. Isso se expressa, por exemplo, quando } \\
\text { dizem que buscam compreender como a adoção da Modelagem implica na aprendizagem da } \\
\text { Matemática. }\end{array}$ \\
\hline
\end{tabular}

Quadro 3 - Síntese do que é dito em cada Núcleo de Ideias

Fonte: Os autores (2020)

Buscando focar os sentidos que se expressam sobre a adoção da Modelagem nos núcleos de ideias constituídos, empreendemos um esforço fenomenológico-hermenêutico de interpretação do dito pelos autores. Stein (2010) diz que interpretar é expor. Interpretar é, para além disso, "[...] explicitar o tipo de ser-no-mundo manifestado diante do texto" (RICOEUR, 2015, p. 65) que materializa o dizer do sujeito.

Lendo, vez após vez, o que diziam as unidades de significado componentes de cada

19 A constituição das unidades de significado e dos núcleos de ideias dessa investigação foi otimizada pela utilização do software de pesquisa qualitativa Atlas ti. Ainda que não substitua o trabalho rigoroso do pesquisador, esse software se mostra como uma ferramenta que atribui agilidade ao movimento de análise e interpretação dos dados produzidos. 
núcleo, acabamos por descrever um movimento hermenêutico de compreensão/interpretação/compreensão que é, segundo Bicudo e Paulo (2011, p. 259),

[...] sustentado pela tensão estabelecida entre: subjetividade do pesquisador que traz consigo seu horizonte de compreensão; a estrutura do texto, que fornece indicadores da sua lógica, que revela o discurso do autor, ou seja sua compreensão do investigado, do que para ele faz sentido e está escrito no texto apresentado para debate; os aspectos históricos do mundo da obra de que o texto fala; e a meta compreensão [...] possibilitada pela discussão entre os pesquisadores envolvidos e autores estudados.

Nesse movimento, procuramos não apenas considerar o que é dito individualmente pelos autores das pesquisas levantadas, mas, da "[...] totalidade dos discursos [desses] sujeitos" (BICUDO, 2011, p. 65, inserção nossa) trazer à clareza, nos próximos subtítulos, o sentido que se expressa pelo que é dito sobre a adoção da Modelagem pela comunidade da Educação Matemática.

\section{Explicitando o que é dito sobre a adoção da Modelagem nas pesquisas produzidas pela comunidade da Educação Matemática}

Explicitar envolve tornar nítido o que está sendo focado. É a essa tarefa que nos dedicamos neste subtítulo. Explicitar a nós mesmos e aos leitores, o que se mostra das unidades de significado cujas convergências resultantes do movimento rigoroso de consideração, levaram a constituição dos 4 núcleos de ideias abertos nesse estudo.

O primeiro núcleo, "NI1-Aspectos que implicam, advém ou se mostram relevantes para a adoção da Modelagem Matemática", é composto por 240 unidades de significado constituídas nos documentos primários P1, P2, P3, P4, P6, P7, P8, P9, P10, P11, P13, P14, P19, P21, P22, P24, P27, P28, P29, P30, P31, P33, P34, P35, P36, P37, P39, P40, P41, P44, P45, P46, P47, P49, P50, P51, P52, P54, P55, P56, P57, P59, P62, P64, P65, P66, P67, P68, P70, P71, P72, P73, P73, P74, P76, P77, P78, P79, P80, P81, P82, P84, P85, P86, P88, P90, P91, P92, P93, P94, P95, P96, P97, P98, P100, P102, P103, P104, P105 e P106.

As unidades que constituem esse núcleo evidenciam, inicialmente, os aspectos tomados pelos autores das pesquisas levantadas como favoráveis e advindos da adoção da Modelagem. Dentre eles, menciona-se a modificação do ritmo de trabalho do professor, o desencadeamento do interesse dos alunos e a ruptura com o ensino usual ${ }^{20}$. Nessa direção destacam-se as unidades 3:6, 57:2, 85:1 e 52:1: Tatsch (2006) menciona que a adoção da Modelagem modifica o ritmo de trabalho do professor, Sonego e Bisognin (2010) adotam a Modelagem visando desencadear

\footnotetext{
${ }^{20}$ Entende-se por usual, o modelo de prática pautado na exposição de conteúdos e na reprodução de exercícios de aplicação.
} 
nos alunos o interesse em aprender, Abdanur (2006) fala que a adoção da Modelagem no ensino propicia melhor desempenho ao aluno, como principal agente de mudança e Burak e Martins (2015) articulam que a adoção da Modelagem pode romper com o modo usual de condução do ensino da matemática.

Ainda que os aspectos supracitados sejam destacados e haja expectativas quanto ao trabalho com a Modelagem na escola, as unidades de significado que compõem esse núcleo mostram que elas podem não ser suficientes para sua adoção. As unidades 98:1 e 7:2 discorrem neste respeito: Chaves (2012) fala do risco de a Modelagem não ser adotada nas aulas de Matemática ainda que haja expectativas geradas pelas vantagens de seu uso e Mutti (2016) afirma que, embora a disposição para a mudança e o caráter plural das práticas dos professores possam contribuir para adoção da Modelagem, eles podem não ser suficientes, pois os contextos de trabalhos por professores podem ser avessos à Modelagem.

Com efeito, as unidades mostram que fatores como as concepções prévias dos professores em relação à Matemática, ao ensino e à organização escolar, podem influenciar a adoção da Modelagem. Para além dessas concepções, explicitam-se deste núcleo aspectos mencionados pelos autores como justificativas para a não adoção da Modelagem e estes incluem: os sentimentos de imediatismo e comodismo, a transposição do ensino tradicional e a postura do professor. Sobre isso destacamos as unidades 8:6, 6:3, 7:26, 39:1, 55:1 e 81:2 que dizem: Silva (2017) entende que Barbosa (2012) fala da influência das concepções prévias na adoção da Modelagem; Ferreira (2010) afirma que o que mais atrapalha a adoção da Modelagem é a resistência do professor em mudar sua concepção sobre a organização escolar; Mutti (2016) exalta que os sentimentos de imediatismo e comodismo podem contribuir para a desistência do trabalho com a Modelagem; Bassanezi (2012) fala que a maior dificuldade encontrada pelos professores que procuram adotar a Modelagem é transpor o ensino tradicional; Tatsch e Bisognin (2007) citam que a adoção da Modelagem interfere no ritmo de trabalho e na postura do professor que precisa libertar-se de programas pré-fixados.

Outro fator evidenciado é o modo como se dá a adoção da Modelagem que, segundo as unidades, pode não ocorrer por opção do professor. Vemos isso na unidade 4:5 na qual Tambarussi (2015) destaca em sua análise que a adoção da Modelagem por um professor cursista do PDE não se deu por opção do professor.

Nesta direção, as unidades falam da formação de professores em Modelagem e ao tratarem dela ressaltam que, ainda que possa contribuir para a minimização das resistências, a incompletude das formações, as políticas de formação restritas ao discurso inicial, o tempo de duração das formações e os encaminhamentos nelas utilizados podem implicar na decisão do 
professor em adotar a Modelagem. Sobre isso, destacam-se as unidades 9:9, 94:6, 86:5, $45: 5$ e 4:16 que inferem: Cararo (2017) afirma que a Formação em Modelagem busca minimizar a resistência dos professores quanto a sua adoção; Souza, (2011), citando Silveira (2007) destaca que o pequeno tempo de formação em Modelagem pode estar contribuindo para que ela não seja adotada; Martens (2018) fala da incompletude das formações em levar o professor a adotar a Modelagem; Mutti (2018) menciona que a reprodução de encaminhamentos ditados por especialistas no contexto da formação pode repercutir na decisão dos professores quanto a adoção da Modelagem; e Tambarussi (2015) infere que nas políticas de formação há apenas um discurso inicial sobre a adoção da Modelagem, sem que haja um trabalho que busque proporcionar conhecimentos mais aprofundados.

O núcleo menciona ainda, como aspectos relevantes para a adoção da Modelagem, a constituição de espaços coletivos de discussão, a proximidade entre os professores, a disposição à experimentação, o reconhecimento e a valorização da multidimensionalidade de suas práticas pedagógicas e o apoio dos pares no contexto de grupos de formação. Esses aspectos se expressam nas unidades 47:2, 22:2, 7:25, 36:1 e 45:7: Cararo e Klüber (2017) afirma que a ruptura do distanciamento entre os professores pode contribuir para a adoção da Modelagem; Martins (2016) salienta que o apoio dos colegas pode encorajar os professores para adotar a Modelagem; Mutti (2016) fala que a disposição para experimentação pode evidenciar uma abertura à adoção da Modelagem; Rosso (2016) chama a atenção ao fato de adoção da Modelagem ser favorecida pelas experiências com grupos de formação e de aspectos teóricos; e Mutti e Klüber (2018) ressaltam que, sendo a adoção da Modelagem um dos objetivos centrais da formação, é necessário que ela valorize a multidimensionalidade de suas práticas.

O núcleo "NI2 - O professor e a adoção da Modelagem sob distintas perspectivas", no que lhe diz respeito, é constituído de 58 unidades de significado, respectivas aos documentos primários $\mathrm{P} 1$, P2, P3, P7, P8, P11, P12, P14, P18, P19, P20, P21, P22, P23, P24, P25, P26, P27, P29, P42, P45, P58, P61, P63, P66, P69, P72, P74, P75, P76, P78, P83, P88, P89, P90, P94, P95, P103 e P107. Essas unidades falam do interesse dos professores pela adoção da Modelagem e enfatizam que, ao experimentar o desenvolvimento de atividades de Modelagem na escola, eles avaliam como se sentem quando consideram sua adoção a partir das diferentes perspectivas mencionadas na literatura. Sobre isso destacamos as unidades 103:1, 61:1, 45:2, 72:23 e 27:3 nas quais: Caron e Müller (2004) apresentam evidências de que os professores estão adotando a Modelagem; Ceolim e Caldeira (2016) falam de um maior interesse dos professores pela adoção da Modelagem; Mutti e Klüber (2018) esclarecem que, quando os professores experimentam diferentes estratégias pedagógicas e avaliam como se sentem em 
relação a adoção da Modelagem se abrem a formar um novo modo de ensinar; Huf (2016) denota que, após a realização de um curso, os professores avaliaram a possibilidade de adoção da Modelagem em suas aulas; e Oliveira (2016) expõe que os professores vêm adotando a Modelagem por meio de diferentes abordagens presentes na literatura.

As unidades constitutivas deste núcleo dizem ainda que os professores devem adotar a concepção de Modelagem mais adequada à sua sala de aula e evidenciam que os autores das pesquisas consideradas dizem adotar a Modelagem como metodologia de ensino, como método de ensino, como alternativa metodológica, como instrumento pedagógico, como estratégia de ensino e como proposta pedagógica. Neste respeito, realçamos as unidades 29:11, 19:1, 24:1, 29:2, 29:7 e 83:1 que articulam: Andrade (2008) diz que cada professor deve adotar a Modelagem segundo a concepção mais adequada para sua sala de aula; Araújo (2008) fala da adoção da Modelagem como estratégia de ensino; Zukauskas (2012) citando Biembengut (2004) fala sobre a adoção da Modelagem como método de ensino; Andrade (2008) fala da Modelagem adotada como instrumento pedagógico e de conceitos, ideias e procedimentos da Matemática; e Matos (2015) cita que a adoção da Modelagem constitui-se como alternativa metodológica para o ensino da Matemática.

Para além disso, as unidades deste núcleo referem-se à adoção da Modelagem na perspectiva da Educação Matemática crítica ou perspectiva sócio-crítica, explicitando que os autores das pesquisas levantadas afirmam adotar a Modelagem segundo as orientações de concepções específicas e mesmo sob diferentes concepções defendidas por pesquisadores da área. Sobre isso trazemos as unidades 2:3,29:5, 12:2 71:1, 29:1 e 95:1: Silveira (2007) afirma adotar na Modelagem na perspectiva da Educação Matemática Crítica; Andrade (2008) fala que em sua pesquisa adota a Modelagem sob a perspectiva sócio-crítica; Brites (2012) alega que adotou a Modelagem na concepção de Biembengut (2004); Bastos e Santos (2016) ressaltam adotar a Modelagem segundo a concepção de Burak (1992); Andrade (2008) fala da adoção de uma concepção de Modelagem; e Teodoro (2018) esclarece adotar a Modelagem na formação sob diferentes concepções.

O último aspecto que se destaca das unidades que compõem esse núcleo diz que a adoção da Modelagem pelos professores envolve o deslocamento de um discurso de receio para um discurso de expectativa voltado ao trabalho com ela na escola. Esse aspecto se mostra da unidade 7:23 na qual Mutti (2016) salienta que houve, entre os professores, o deslocamento de um discurso de receio para um discurso de expectativa quanto a adoção da Modelagem.

O núcleo "NI3 - O discurso de incentivo, critérios norteadores e a produção de materiais visando a adoção da Modelagem" é constituído de 44 unidades de significado estabelecidas dos 
documentos primários P1, P3, P4, P5, P6, P7, P9, P10, P20, P21, P22, P24, P28, P31, P32, P36, P38, P42, P43, P45, P51, P53, P56, P58, P59, P74, P78, P86, P90, P97, P99, P106 e P107. Estas unidades dizem que existe nos documentos oficiais e na literatura nacional e internacional, o discurso voltado à adoção da Modelagem. Nesta direção sobressaem-se as unidades de significado 4:1, 90:3, 99:1, 107:4, 10:1: Tambarussi (2015) destaca que existem na comunidade reflexões sobre a adoção da Modelagem em sala de aula; Carvalho (2011) fala do incentivo dos pesquisadores à adoção da Modelagem; Luna (2012) cita que os estudos de Doerr e English (2006); Antonius et al. (2007) e Leiß, (2005) mostram a relevância da adoção da Modelagem por professores da Educação Básica; Silva (2018) menciona que a adoção da Modelagem encontra subsídios nas diretrizes para a formação de professores; Kovalski (2016) afirma que os PCN e a BNCC são favoráveis à adoção da Modelagem.

As unidades ressaltam, entretanto, que apenas o discurso de incentivo pode ser ineficiente para que a adoção da Modelagem aconteça. São, desse modo, frisados critérios e a produção de materiais que, respectivamente, norteiam e fornecem subsídios à adoção. Concernente a isso, salientamos as unidades 43:1, 4:14, 31:2, 5:2 e 22:9, que inferem: Burak (1994) discute os critérios norteadores para a adoção da Modelagem; Tambarussi (2015) cita Barbosa (2001) e ressalta que apenas o discurso de incentivo ao trabalho com a Modelagem tem se mostrado ineficiente para a sua adoção; Gaebler e Veronez (2010) mencionam que em Almeida (2002) encontram orientações par a adoção da Modelagem na sala de aula; Scheller (2009) destaca que o material que elaborou durante sua pesquisa visa fornecer subsídios para que professores que adotam o trabalho com a Modelagem; e Martins (2016) declara que a produção de um material de apoio aos professores para adotarem a Modelagem passou a ser alvo coletivo do grupo.

O último núcleo "NI4 - A adoção da Modelagem mencionada dentre os focos, objetivos e resultados de pesquisa", por sua vez, emerge das convergências estabelecidas entre 43 unidades de significado que foram produzidas da reescrita de excertos dos documentos primários P2, P3, P4, P6, P7, P8, P9, P12, P17, P22, P29, P31, P32, P48, P53, P55, P60, P72, P75, P87, P91, P94, P97, P101, P107, P108 e P109. As unidades 2:2, 3:4, 7:4, 8:2 e 9:4, que compõem esse núcleo evidenciam a referência feita à adoção da Modelagem dentre os focos e objetivos das pesquisas: Silveira (2007) procura, em sua pesquisa, analisar o crescimento político dos estudantes ao adotarem a Modelagem como estratégia de ensino-aprendizagem; Tatsch (2006) interroga em sua dissertação se a adoção da Modelagem no Ensino Médio contribui para o aprendizado de conceitos de função e estatística; Mutti (2016) buscou compreender como as práticas pedagógicas de professores num contexto de formação implicam 
na adoção ou não da Modelagem; Silva (2017) interrogou como as concepções prévias dos professores interferem na adoção da Modelagem; e Cararo (2017) buscou compreender o sentido da Formação para a adoção da Modelagem.

A adoção da Modelagem também é expressa pelos autores nos resultados de suas pesquisas. Alguns deles são: a apresentação de aspectos significativos da adoção da Modelagem, a necessidade da realização de pesquisas que se voltem para os desafios à adoção da Modelagem, o pequeno número de pesquisas que discutem a adoção da Modelagem nos Anos Iniciais e as implicações pedagógicas e científicas da adoção da Modelagem no ensino. Nesse sentido, as unidades 6:1, 7:28, 53:2 e 72:5 encerram: Ferreira (2010) denota que os resultados de sua pesquisa apresentam aspectos significativos da adoção da Modelagem na Educação Básica; Mutti (2016) fala da necessidade de pesquisas que se voltem para os desafios à adoção da Modelagem; Souza e Luna (2014) destacam o pequeno número de pesquisas que discutem a adoção da Modelagem em Anos Iniciais; e Huf (2016) apontou as implicações pedagógicas e científicas da adoção da Modelagem em relação ao ensino e aprendizagem de Matemática.

Ao passo que considerávamos atentivamente o que diziam as unidades de significado constitutivas dos núcleos de ideias que acabamos de explicitar, nos envolvíamos num “[...] movimento do pensar que se realiza efetuando insights, abstrações, comparações, articulações, reunindo e separando aspectos, expressando o compreendido pela linguagem” (BICUDO, 2011, p. 59). Desse movimento emergiram as interpretações que apresentamos no subtítulo a seguir.

\section{Adoção da Modelagem Matemática como expressa na literatura em Educação Matemática: uma síntese compreensiva}

Buscar pela explicitação de uma síntese compreensiva envolve falar do ato de compreender. Paul Ricoeur (2011, p. 68, inserção nossa e grifos do autor) diz que compreender

[...] não se trata de impor ao texto [nossa] própria capacidade finita de compreender, mas de expor-se ao texto e receber dele um si mais amplo, que seria a proposição de existência respondendo, da maneira mais apropriada possível, à proposição de mundo.

Sendo assim, quando nos colocamos a interrogar, abrimo-nos à proposição de mundo que se encontra diante do texto das unidades de significado que constituem os 4 núcleos de ideias abertos nessa pesquisa. Ao fazer isso, abrimo-nos ao que essas unidades desvelam sobre a adoção da Modelagem Matemática, quando expressa na literatura produzida no âmbito da 
Educação Matemática. Desse movimento, emergiram compreensões sobre as quais discorreremos nesse subtítulo.

A primeira delas, apresentada na introdução deste artigo como um aspecto que atesta a pertinência de nos dedicarmos a essa temática, é a ausência evidenciada pela análise dos focos e objetivos das 109 pesquisas levantadas, de iniciativas que tomem a adoção da Modelagem Matemática como fenômeno ou objeto de estudo.

Isso vem à clareza quando no núcleo NI4, olhamos para pesquisas nacionais e internacionais como as de Mutti (2016), Cararo (2017), Martins (2016), Barasuol (2006) e Geiger (2011), que focam a Modelagem buscando compreender, respectivamente: como as práticas pedagógicas dos professores implicam na sua adoção; o sentido da formação para a adoção; como o apoio dos pares pode potencializar a adoção e quais as vantagens da adoção e os fatores que podem afetá-la. Vem à clareza ainda, quando atentamos para os documentos norteadores das políticas públicas de ensino e de formação de professores, mencionados no núcleo NI3.

Em ambos os núcleos, vemos que as menções à adoção da Modelagem estão focadas, predominantemente, nos aspectos que podem contribuir, dificultar ou advir do trabalho com a Modelagem na escola. Corroborando com isso, o núcleo NI3 evidencia ainda os esforços de pesquisadores da área da Educação Matemática, em estabelecer critérios norteadores e produzir materiais didáticos que permitam subsidiar a adoção da Modelagem, colaborando para que os professores possam fazer dessa tendência uma prática constante em suas aulas.

Embora a pertinência dessas iniciativas, destacadamente, as relacionadas aos critérios e os materiais didáticos, possa ser reconhecida no sentido de orientar os professores quanto às particularidades inerentes ao movimento de elaboração e desenvolvimento de atividades de Modelagem inéditas ou sugeridas na literatura, vê-se que nelas as atenções estão voltadas para os procedimentos, ou seja, para o modo de fazer, para o como conduzir o trabalho com a Modelagem na escola, não sendo evidenciadas discussões que visem compreender a adoção da Modelagem em seu profundo sentido.

Ao passo que ponderamos acerca disso, parece se expressar da literatura no contexto da Educação Matemática a compreensão da adoção da Modelagem numa atitude natural, isto é, as discussões apresentadas nas pesquisas analisadas tomam a adoção como uma necessidade da própria Modelagem, mas, por vezes, desarticulada daquele a quem essa adoção se dirige: o professor.

Embora entendamos que os argumentos sobre a adoção da Modelagem, expressos no núcleo NI1, pertençam legitimamente à Modelagem e à pesquisa sobre ela, eles não dizem sobre 
o movimento de adoção dela por parte dos professores. Dizem, por outro lado, de características mais gerais necessárias à sua adoção, de modo que, quando damos um passo para trás e interrogamos como a Modelagem é adotada, vemos que essa interrogação não depende exclusivamente da Modelagem, ela volta-se para o professor.

Queremos dizer com isso que compreender a adoção da modelagem não é possível apenas considerando as pesquisas que mencionam sua adoção de uma ou outra perspectiva. É preciso, para compreendê-la, ir ao professor. Ou seja, quem adota ou não a Modelagem na sala de aula é o professor. Então é relevante interrogar o que é, para ele, essa adoção da Modelagem.

Buscar compreender a adoção da Modelagem com a atenção dirigida ao professor, mostra-se ainda mais pertinente quando consideramos o fato de o núcleo NI1 ter evidenciado a possibilidade de os aspectos tomados como favoráveis e a expectativa proveniente do trabalho com a Modelagem na escola não se mostrarem suficientes para sua adoção.

Ser suficiente diz de imbuir-se de disposição para realizar algo, sentindo-se capaz de, segundo a etimologia dessa palavra, descrever o movimento de "pôr em lugar de [...] fazer" (HOUAISS, 2019, p. 1, grifos nossos). Sendo assim, quando refletimos sobre o que os autores dizem quanto ao fato de os aspectos favoráveis do trabalho com a Modelagem na sala de aula, não se mostrarem suficientes para que os professores a tomem como possibilidade em sua prática pedagógica cotidiana, entendemos que, ainda que os façam sentir inicialmente motivados (KLÜBER et al., 2016), esses aspectos podem acabar não fornecendo aos professores subsídios que os permitam compreender como podem colocar a Modelagem em prática e, mais do que isso, fazer dela parte de sua prática .

Entendemos que fazer da Modelagem parte de sua prática pode requerer, num primeiro momento, que o professor tome uma decisão no sentido de admitir o trabalho com ela na sala de aula. Essa decisão, por sua vez, talvez solicite disposição em reunir os meios necessários para colocá-la em prática. Esses meios talvez envolvam buscar compreender a Modelagem do ponto de vista teórico e desenvolver habilidades relacionadas ao como implementá-la na escola. Destacamos, entretanto, que esse como deve ser considerado para além da ideia, por vezes ingênua, de que é possível, ao se trabalhar com Modelagem, simplesmente reproduzir procedimentos ditados pela literatura. Falamos aqui da relevância de pensar o como no sentido de perguntar: de que modo o professor pode desenvolver atividades de Modelagem no seu contexto particular de trabalho?

Falamos ainda da necessidade de o professor refletir, assim como infere Mutti (2016), sobre os aspectos característicos de suas práticas pedagógicas que podem necessitar de alterações para que a Modelagem possa ser considerada e, até mesmo, vivenciar experiências 
com a Modelagem com o apoio de pares a partir de distintas perspectivas, como mostrou o núcleo NI2.

O fato é que, do ponto de vista do professor, pôr a Modelagem em lugar de, isto é, abrirse à possibilidade de pensar a prática pedagógica para além dos aspectos paradigmáticos que a compõe ${ }^{21}$ e, sentindo-se capaz de fazer da Modelagem parte integrante de seu trabalho em sala de aula, pode solicitar mais do que atentar ao discurso de incentivo voltado à sua adoção, como expresso no núcleo NI3. Talvez envolva considerar: por que seria importante para eu (professor) e para meus alunos trabalhar com a Modelagem? O que me motiva a fazer isso? Do que necessito para que ela possa se tornar uma prática habitual? Ou mesmo, o que me ajuda a não desistir de continuar trabalhando com a Modelagem na sala de aula?

Essas considerações, além de fortalecer nossas convicções quanto a pensar a adoção da Modelagem como estritamente vinculada ao professor, nos movem a ponderar sobre o modo como alguns dos pesquisadores no âmbito da Educação Matemática têm se referido à adoção em suas pesquisas. Pensemos, por exemplo, na asserção presente no núcleo NI1, quando na unidade 4:5 destaca-se "que a adoção da Modelagem por um professor cursista do PDE não se deu por opção do professor".

No excerto dois termos se merecem destaque: opção e adoção. Optar, diz respeito a possibilidade de poder escolher livremente, enquanto adotar envolve admitir espontaneamente (HOUAISS, 2019). Ambas as expressões, em seus sentidos originais, remetem a uma ação que tem como cerne a tomada de decisão influenciada pelas preferências particulares daquele que decide. Logo, a palavra adoção parece ser utilizada no excerto de modo natural, isto é, corroborando com a compreensão de que o trabalho com a Modelagem decorre de uma perspectiva externa e não daquele que efetivamente a desenvolve na escola.

Ao dizermos perspectiva externa referimo-nos a atitude, talvez ingênua, decorrente de um modo de compreender a prática do professor que considera suficiente dar-lhe procedimentos de ação, ou seja, cursos ou mesmo oficinas nos quais tenha contato com a Modelagem, para que ela se imponha a ele como método de ensino e ele se sinta motivado a adotá-la em sua prática docente.

Precisamos considerar que, ainda que a formação e o trabalho com o apoio dos pares possam motivar o professor a desenvolver a Modelagem em suas aulas, entendemos, como já dissemos, que admiti-la como parte integrante de sua prática é uma decisão que, em última instância, depende do professor.

${ }^{21}$ Como o paradigma do exercício mencionado por Skovsmose (2000). 
Quando, por outro lado, se cogita a adoção da Modelagem como um movimento proveniente da decisão de outro que não seja o próprio professor, incorre-se na possibilidade de conceber a adoção como um movimento no qual toma-se a Modelagem e, destacadamente, seus aspectos entendidos como favoráveis do ponto de vista do processo de ensino e aprendizagem da Matemática, como elementos capazes de, por si só, fazer com que o professor esteja disposto a levá-la para a sala de aula. Em síntese, considera-se a adoção da Modelagem como decorrente da própria Modelagem e não daquele que decide levá-la para escola, o professor.

Entendemos que, por mais que possam nortear o desenvolvimento das atividades de Modelagem, os procedimentos mencionados na literatura acabam, frequentemente, sendo reconfigurados de modo a atender as necessidades específicas do professor e de seu contexto de atuação. Assim sendo, parece pertinente considerar que a adoção da Modelagem pode não decorrer dos procedimentos, eles são, por outro lado, solicitados quando há, previamente, a disposição do professor em colocá-la em prática.

A disposição dos professores frente ao trabalho com a Modelagem é, inclusive, destacada nos núcleos NI1 e NI2, quando os autores dizem que há evidências de que os professores estão adotando a Modelagem e de que eles avaliam como se sentem quando a desenvolvem na escola e, somente então, se abrem a um novo modo de ensinar. Esses núcleos de ideias ressaltam ainda que buscar valorizar a multidimensionalidade das práticas pedagógicas dos professores pode contribuir para que adotem a Modelagem. Mais uma vez, vemos que as unidades lançam luzes sobre os professores.

Ainda que, ao longo de três décadas, as pesquisas voltadas à Modelagem produzidas no âmbito da Educação Matemática tenham delineado um movimento predominantemente dirigido aos aspectos favoráveis, aos desafios e as necessidades da própria Modelagem - o que era de se esperar, sendo essa uma área de pesquisa jovem que, como tal, buscava conhecer a si mesma - quando voltamo-nos para elas interrogando o que dizem sobre a adoção da Modelagem, vemos que, unanimemente, elas vinculam a adoção ao professor e à sua decisão.

As compreensões expressas nesse artigo, em particular, as que trazem à clareza o vínculo entre o professor, sua decisão e a adoção da Modelagem revelam, em última instância, que entender o que fazer para que sejam ampliadas as iniciativas de trabalho com a Modelagem na escola envolve não negligenciar, em suas múltiplas dimensões, quem a adota: o professor.

\section{Considerações}

Assumindo a postura fenomenológica de investigação, voltamo-nos para as pesquisas 
sobre Modelagem Matemática produzidas pela comunidade da Educação Matemática. Ao interrogarmos o que elas dizem sobre a adoção da Modelagem vimos que, como fenômeno, ela ainda permanece não tematizada.

Há, por outro lado, um discurso de incentivo dirigido à adoção da Modelagem e, em síntese, a maior parte das pesquisas consideradas revelam, em seus focos e objetivos, buscar pela elaboração de critérios que possam orientar o trabalho com a Modelagem na escola e pela compreensão dos aspectos favoráveis e dos desafios que podem advir dessa iniciativa, quando realizada na sala de aula.

É notório, entretanto, o fato de as 109 pesquisas consideradas concordarem quando se fala sobre a relevância do professor quanto à possibilidade de adoção da Modelagem. E é assim, reconhecendo o professor como aquele que pode aproximar a Modelagem da escola, que esse estudo traz à tona a urgência de buscarmos compreender a adoção da Modelagem para além dos procedimentos.

Dizemos isso, pois, as pesquisas explicitaram que as concepções dos professores podem influenciar suas decisões quanto à adoção da Modeladem. Evidenciaram ainda que os professores avaliam como se sentem ao trabalhar com a Modelagem, decidindo se irão ou não se abrir a uma nova prática e, para além disso, que a valorização da multidimensionalidade das práticas dos professores pode contribuir para que eles a adotem. Essas considerações nos levam a inferir que precisamos, como área, ampliar nossas discussões de modo a pensar a adoção da Modelagem segundo aquele que a adota, o professor.

Diante disso, a principal contribuição que a pesquisa trouxe consiste em abrir a possibilidade de problematizar, esclarecer e compreender aspectos que, embora sejam tomados em uma atitude positiva frente à adoção da Modelagem, mostram-se insuficientes, pois as assertivas sobre ela assentam-se em uma visão especializada da própria área, não levando em conta o dinâmico e complexo movimento da historicidade e da praxis humana. Em suma, o professor é visto como alguém que dispõe de elementos para adotar a Modelagem, mas esta visão foca os elementos que a ela são próprios e não o professor em si, como aquele que a adota. Esse olhar orientado numa tradição de pesquisa e ciência com fundo epistemológico de causa e efeito, desconsidera aspectos ontológicos, como o horizonte de compreensão de todo aquele que se aproxima e se abre a algo novo, podendo tomá-lo para si ou rejeitá-lo.

Sendo assim, finalizamos esse texto do mesmo modo que o iniciamos, com uma inquietação: o que é a adoção da Modelagem Matemática para o professor? Essa inquietação, emerge como necessidade no âmbito da comunidade da Educação Matemática e, como tal, como possibilidade de pesquisa por aqueles que tomam a Modelagem Matemática ou mesmo a 
formação de professores em Modelagem Matemática como região de inquérito.

\section{Referências}

ABDANUR, P. Modelagem Matemática: uma metodologia alternativa de ensino e aprendizagem. 2006. 146 f. Dissertação (Mestrado em Educação) - Setor de Ciências Humanas, Letras e Artes, Universidade Estadual de Ponta Grossa, Ponta Grossa, 2006.

ABREU, G. O. C. de. A prática de modelagem matemática como um cenário de investigação na formação continuada de professores de matemática. 103 f, 2011. Dissertação (Mestrado em Educação Matemática) - Universidade Federal de Ouro Preto, Ouro Preto, 2011.

ALMEIDA, L. M. W. Modelagem Matemática na sala de aula: um estudo. Anais... eletrônicos do VII EPREM-Encontro Paranaense de Educação Matemática, Foz do Iguaçu, Pr, 2002.

ALMEIDA, L. W. A.; SILVA, K. P.; VERTUAN, R. E. Modelagem matemática na educação básica. São Paulo: Contexto, 2012.

ALVES, A. de O. Contribuições da modelagem matemática para a formação do senso investigativo na EJA. 2018. Trabalho de Conclusão de Curso (Graduação em Licenciatura em Matemática) - Faculdade de Matemática, Universidade Federal do Pará, Castanhal, 2018.

ANDRADE, M. M. Ensino e aprendizagem de estatística por meio da modelagem matemática: uma investigação com o ensino médio. 196 f. 2008. Dissertação (Mestrado em Educação Matemática) - Instituto de Geociências e Ciências Exatas, Universidade Estadual Paulista, 2008.

ANTONIUS et al. Classroom activities and the teacher. In: BLUM, W. et. al. (Org.) Modelling and applications in mathematics education: the 14th ICMI study. New York: Springer, 2007. p. 295-398.

ARAÚJO, A. M. R. Modelagem Matemática nas aulas de cálculo: Uma estratégia que pode contribuir com a aprendizagem dos alunos de engenharia. 96 f, 2008. Dissertação (Mestrado em Educação em Ciências e Matemáticas) - Universidade Federal do Pará, Belém, 2008.

BARALDI, I. M.; JAVARONI, S. L.; FINATO, J. A. R.; COELHO, K. R. Uma experiência saudável: narrativas e modelagem matemática na formação de professores de matemática. In: XI Congresso Estadual Paulista sobre formação de professores e I Congresso Nacional de formação de professores, Águas de Lindóia - SP Anais... São Paulo: Prograd - UNESP p.1602-1611, 2011.

BARASUOL, F. F. Modelagem matemática: uma metodologia alternativa para o ensino da matemática. UNIrevista, São Leopoldo, v. 01, n. 02, p. 1-6, 2006.

BARBOSA, A. A. S. Modelagem matemática: relatos de professores. 208 f. 2012. Tese (Doutorado em Educação Matemática) - Universidade Federal do Paraná, Curitiba, 2012.

BARBOSA, J. C. Modelagem Matemática: concepções e experiências de futuros professores. $273 \mathrm{f}$. 2001. Tese (Doutorado em Educação Matemática) - Instituto de Geociências e Ciências Exatas, Universidade Estadual Paulista "Júlio de Mesquita Filho", Rio Claro, 2001.

BARROS, S. S. A modelagem matemática no ensino da matemática financeira. 2010. Trabalho de Conclusão de Curso (Especialização em Matemática Financeira: ensino e empresarial) - Faculdade de Ciências Contábeis e Administração do Vale do Juruena, Alta Floresta, 2010.

BASSANEZI, R. C. Temas e modelos. São Paulo: Editora Unicamp, 2012. 
BASTOS, A. R.; SANTOS, S. A. Modelagem matemática na formação inicial de docentes: perspectivas para o ensino de matemática na educação básica. Produto Educacional, Universidade Estadual do Centro-Oeste, Guarapuava, 2016, p. 1-31.

BELLEI, P. Gestão escolar e formação de professores em modelagem matemática na educação matemática: um olhar. 120 f. 2018. Dissertação (Mestrado em Ensino) - Universidade Estadual do Oeste do Paraná, Foz do Iguaçu, 2018.

BELLEI, P.; KLÜBER, T. E. Comunidade escolar e modelagem matemática na educação matemática: uma reflexão. Actio, Curitiba, v. 3, n. 3, p. 317-335, set./dez. 2018.

BELTRÃO, M. E. P. Ensino de cálculo pela modelagem matemática e aplicações: teoria e prática. 330 f. 2009. Tese (Doutorado em Educação) - Pontifícia Universidade Católica de São Paulo, São Paulo, 2009.

BELTRÃO, M. E. P.; IGLIORI, S. B. C. Modelagem matemática e aplicações: uma abordagem para o ensino de funções. Educação Matemática Pesquisa, São Paulo, v. 12, n. 1, p. 17-42, 2010.

BICUDO, M. A. V. A pesquisa qualitativa fenomenológica: interrogação, descrição e modalidades de análise. In: Maria Aparecida Viggiani Bicudo. (Org.). Pesquisa qualitativa segundo a visão fenomenológica. $1^{\mathrm{a} e d}$. São Paulo: Editora Cortez, 2011, p. 41-74.

BICUDO; M. A. V.; PAULO, R. M. Um Exercício Filosófico sobre a Pesquisa em Educação Matemática no Brasil. Bolema, Rio Claro, v. 25, n. 41, p. 251-298, dez. 2011.

BIEMBENGUT, M. S. Modelagem matemática \& Implicações no Ensino e na Aprendizagem de Matemática. Ed. da FURB, 2004.

BONOTTO, D. L. (Re)configurações do agir modelagem na Formação Continuada de Professores de Matemática da Educação Básica. 310 f. 2017. Tese (Doutorado em Educação em Ciências e Matemática) - Pontifícia Universidade Católica do Rio Grande do Sul, Porto Alegre, 2017.

BRASIL. Base Nacional Comum Curricular. Brasília: MEC, 2018.

BRASIL. Resolução no 01 de 1 de julho de 2015. Institui as Diretrizes Curriculares Nacionais para a formação inicial em nível superior (cursos de licenciatura, cursos de formação pedagógica para graduados e curso de segunda licenciatura) e para a formação continuada. Conselho Nacional de Educação. Brasília: MEC, 2015.

BRITES, E. M. A. Modelagem matemática gráfica: instigando o senso criativo dos estudantes do ensino fundamental. 154 f. 2012. Dissertação (Mestrado em Ciências e Matemática) - Pontifícia Universidade Católica do Rio Grande do Sul, Porto Alegre, 2012.

BROWN, R. Mathematical modelling in the international baccalaureate, teacher beliefs and technology usage, Teaching Mathematics and its Applications: An International Journal of the IMA, v. 21, n. 2, p. 67-74, 2002.

BUENO, V. C. Concepções de modelagem matemática e subsídios para a educação matemática: quatro maneiras de compreendê-la no cenário brasileiro. 130 f. 2011. Dissertação (Mestrado em Educação Matemática) - Universidade Federal de Ouro Preto, Ouro Preto, 2011.

BURAK, D. Critérios norteadores para a adoção da Modelagem Matemática no ensino fundamental e secundário. Zetetiké, Campinas, v. 2, n. 2, p. 47-60, 1994. 
BURAK, D. Modelagem Matemática sob um olhar de Educação Matemática e suas implicações para a construção do conhecimento matemático em sala de aula. Revista de Modelagem na Educação Matemática, Blumenau, v. 1, p. 10-27, 2010.

BURAK, D. Modelagem matemática: ações e interações no processo de ensino-aprendizagem. $460 \mathrm{f}$. 1992. Tese (Doutorado em Educação) - Universidade Estadual de Campinas, Campinas, 1992.

BURAK, D. Uma perspectiva de modelagem matemática para o ensino e aprendizagem da matemática. In: BRANDT, C. F.; BURAK, D.; KLÜBER, T. E. (org.). Modelagem Matemática: perspectivas, experiências, reflexões e teorizações. 2. ed. Ponta Grossa: Editora UEPG, 2016. p. 17-40.

BURAK, D. Uma perspectiva de Modelagem Matemática para o ensino e aprendizagem da Matemática. In: BRANDT, C. F.; BURAK, D.; KLÜBER, T. E. (org.). Modelagem matemática: perspectivas, experiências, reflexões e teorizações. 2. ed. Ponta Grossa: Editora UEPG, 2016. p. 33-50. Disponível em: http://books.scielo.org/id/b4zpq/pdf/brandt-9788577982325-02.pdf LINK. Acesso em: 12 de fev. 2018.

BURAK, D.; KLÜBER, T. E. Modelaje Matemático en la Educación Básica: Trayectoria de una Concepción. In: BIEMBENGUT, M. S.; SPINADEL, V. W. (Org.). Mathematics \& Design: Fifth International Mathematics \& Design Conference - V M\&D. 1ed. Blumenau: Nova Letra, 2007, v. 1, p. 401-408.

BURAK, D. Modelagem Matemática e a Sala de Aula. In: I EPEM-Encontro Paranaense da Modelagem Na Educação Matemática, 2004, Londrina. Anais...Londrina: UEL, 2004. p. 1-7.

BURAK, D.; MARTINS, M. A. Modelagem Matemática nos anos iniciais da Educação Básica: uma discussão necessária. Revista Brasileira de Ensino de Ciência e Tecnologia, Guarapuava, v. 8, n. 1, p. 93-111, 2015.

BURAK, D.; VOSGERAU, D. S. R.; KLÜBER, T. E. Metanálise dos artigos de modelagem matemática. In: GT-10 do III Seminário Internacional de Pesquisa em Educação Matemática. Cadernos de Educação, n. 52, 2015.

CAMPOS, I. S. A divisão do trabalho no ambiente de aprendizagem de Modelagem Matemática segundo a Educação Matemática Crítica, 255 f. 2018. Tese (Doutorado em Educação) Universidade Federal de Minas Gerais, Belo Horizonte, 2018.

CAMPOS, I. S. A divisão do trabalho no ambiente de aprendizagem de modelagem matemática segundo a educação matemática crítica. 255 f. 2018. Tese (Doutorado em Educação) Universidade Federal de Minas Gerais, Faculdade de Educação, Belo Horizonte, 2018.

CARARO, E. F. F. O sentido da formação continuada em modelagem matemática na educação matemática desde os professores participantes. 2017. Dissertação (Mestrado em Educação) Universidade Estadual do Oeste do Paraná, Cascavel, 2017.

CARARO, E. F. F.; KLÜBER, T. E. O sentido de um modelo de formação continuada em Modelagem Matemática. Boletim do LABEM, Niterói, v. 8, n. 14, p. 143-161, 2017.

CARON, F.; MULLER, E. Integrating Applications and Modelling in Secondary and Post-secondary Mathematics. In: Proceedings of the 28th Annual Meeting of the Canadian Mathematics Education Study Group. 2005. p. 63-80.

CARVALHO, E. M. O uso da modelagem matemática na formação de professoras de Matemática da Educação Básica. 186 f. 2014. Dissertação (Mestrado em Educação Matemática) Universidade Estadual da Paraíba, Campina Grande, 2015. 
CARVALHO, J. C. Um olhar sobre as atividades de Modelagem Matemática a partir da dialética dos ostensivos e não ostensivos. 164f. 2011. Dissertação (Mestrado em Educação em Ciências e Matemáticas) - Universidade Federal do Pará, Belém, 2011.

CARVALHO, J. C. Um olhar sobre as atividades de Modelagem Matemática a partir da dialética dos ostensivos e não ostensivos. 164 f. 2011. Dissertação (Mestrado em Educação em Ciências e Matemáticas) - Universidade Federal do Pará, Belém, 2011.

CEOLIM, A. J. Modelagem matemática na educação básica: obstáculos e dificuldades apontados por professores. 151 f. 2015. Tese (Doutorado em Educação) - Universidade Federal de São Carlos, São Carlos, 2015.

CEOLIM, A. J.; CALDEIRA, A. D. Modelagem Matemática na Educação Básica: dificuldades apresentadas pelos professores recém-egressos formados em Modelagem na perspectiva da Educação Matemática. Revista NUPEM, Rio de Janeiro, v. 8, n. 15, p. 121-136, 2016.

CHAVES, M. I. A. Percepções de professores sobre repercussão de suas experiências com modelagem matemática. 132 f. Tese (Doutorado em Educação em Ciências e Matemática) Universidade Federal do Pará, Belém, 2012.

COSTA, F. A. Ensino matemática por meio da modelagem matemática. Ensino da Matemática em Debate, São Paulo, v. 3, n. 1, p. 58-69, 2016.

COZZA, F. E. Modelagem matemática: percepção e concepção de licenciandos e professores. 97 f. 2013. Dissertação (Mestrado em Educação em Ciências e Matemática) - Pontifícia Universidade Católica do Rio Grande do Sul, Porto Alegre, 2013.

DIAS, M. R. Uma experiência com modelagem matemática na formação continuada de professores. 121 f. 2005. Dissertação (Mestrado em Ensino de Ciências e Educação Matemática) Universidade Estadual de Londrina, Londrina, 2005.

DOERR, H. M.; ENGLISH, L. D. Middle grade teachers "learning through students" engagement with modelling tasks. Journal of Mathematics Teacher Education, New York, v. 9, n. 1, p. 5-32, 2006. e dificuldades apontados por professores. 151 f. 2015. Tese (Doutorado em Educação) - Universidade Federal de São Carlos, São Carlos, 2015.

FERREIRA, A. R. Práticas de numeramento, conhecimentos escolares e cotidianos em uma turma de ensino médio da educação de pessoas jovens e adultas. 142 f. 2009. Dissertação (Mestrado em Educação) - Universidade Federal de Minas Gerais, Belo Horizonte, 2009.

FERREIRA, C. R. Modelagem matemática na Educação Matemática: contribuições e desafios à Formação Continuada de professores na modalidade Educação à Distância Online. 100 f. 2010. Dissertação (Mestrado em Educação) - Universidade Estadual de Ponta Grossa, Ponta Grossa, 2010.

FERREIRA, M. L. A Modelagem Matemática como ferramenta no ensino e aprendizagem dos conceitos matemáticos destinados a formação técnica/tecnológica. 142 f. 2009. Dissertação (Mestrado em Gestão e Desenvolvimento da Gestão Tecnológica) - Centro Estadual de Educação Tecnológica Paula Souza, São Paulo, 2009.

FONER, R. Modelagem matemática e o legado de Paulo Freire: relações que se estabelecem com o currículo. 201 f. 2018. Tese (Doutorado em Educação Matemática) - Instituto de Geociências e Ciências Exatas, Universidade Estadual Paulista "Júlio de Mesquita Filho", Rio Claro, 2018. 
FURTADO, A. B. Modelagem Matemática com tecnologias de informação e comunicação. In: Encontro Paranaense de Modelagem Matemática, 3., 2010, Curitiba. Anais... Curitiba: UTFPR, 2010. p. 1-31.

GAEBLER, R.; VERONEZ, M. R.D Modelagem Matemática na Análise da Estrutura de uma Ponte. In: Encontro Paranaense de Modelagem em Educação Matemática, 4., 2010, Maringá. Anais... Maringá: UEM, 2010. p. 1-11.

GARNICA, A. V. M. Algumas notas sobre pesquisa qualitativa e fenomenologia. InterfaceComunicação, Saúde e Educação, São Paulo, v. 1, n. 1, p. 109-122, 1997.

GAZZETTA, M. A Modelagem como Estratégia de Aprendizagem da Matemática em Cursos de Aperfeiçoamento de Professores. Dissertação (Mestrado em Educação Matemática) - Universidade Estadual Paulista, Rio Claro, 1989.

GEIGER V. Factors Affecting Teachers' Adoption of Innovative Practices with Technology and Mathematical Modelling. In: KAISER, G.; BLUM, W.; BORROMEO, F. R.; STILLMAN, G. (eds.). Trends in Teaching and Learning of Mathematical Modelling: International Perspectives on the Teaching and Learning of Mathematical Modelling, v. 1, Dordrecht: Springer, 2011. p. 305-314.

GEIGER V. Factors Affecting Teachers' Adoption of Innovative Practices with Technology and Mathematical Modelling. In: KAISER, G.; BLUM, W.; BORROMEO, F. R.; STILLMAN, G. (eds) Trends in Teaching and Learning of Mathematical Modelling. International Perspectives on the Teaching and Learning of Mathematical Modelling, v. 1. Springer, Dordrecht, 2011. p. 305-314.

GEIGER, V.; FREJD, P. A reflection on mathematical modelling and applications as a field of research: Theoretical orientation and diversity. In: STILLMAN, G.; BLUM, W.; BIEMBENGUT, M. S. (org.). Mathematical modelling in education research and practice. Cham: Springer, 2015. p. 161-171.

GOMES, G. F.; SILVA, K. A. P. Registros de representação semiótica em uma atividade de modelagem matemática desenvolvida no $1^{\circ}$ ano do ensino médio. In: ENCONTRO NACIONAL DE EDUCAÇÃO MATEMÁTICA ENEM, 11., 2013, Curitiba. Anais... Curitiba: SBEM, 2013. p. 1-14.

GONÇALVES, A. L. Um estudo sobre a importância da modelagem matemática como metodologia de ensino. 2010. Trabalho de Conclusão de Curso (Graduação em Matemática) Instituto Superior de Educação, Faculdade Alfredo Nasser, Aparecida de Goiânia, 2010.

GONÇALVES, K. L. N.; MACHADO JR, A. G. Modelagem matemática como estratégia de ensino e aprendizagem de matemática nas séries iniciais: caminhos reflexivos. In: Conferência Interamericana de Educação Matemática, 13., 2011, Recife. Anais... Recife: IACME, 2011. p. 1-13.

GRIMALDI, F. C. A modelagem matemática na merenda escolar nos anos finais do ensino fundamental, 2015. Dissertação. 110 f. Dissertação (Mestrado profissional em Ensino das Ciências na Educação Básica) - Universidade do Grande Rio, UNIGRANRIO, Duque de Caxias, 2015.

GRIMALDI, F. C.; VICTER, E. F.; RODRIGUES, C. K. A modelagem matemática na merenda escolar: contribuições de um produto educacional. Revista de Educação, Ciências e Matemática, São Paulo, v. 8, n. 1, p. 171-184, 2018.

HEIDEGGER, M. Ser e tempo. v. 1. Petrópolis: Vozes, 2015.

HOUAISS, A. Dicionário de Língua Portuguesa. São Paulo: Objetiva, 2019. Disponível em: https://houaiss.uol.com.br/pub/apps/www/v3-3/html/index.php\#3. Acesso em: 12 jan. 2019. 
HUF, S. F. Modelagem na educação matemática no $9^{\circ}$ ano do ensino fundamental: uma perspectiva para o ensino e a aprendizagem. 2016. Dissertação (Mestrado em Ensino de Ciências Naturais e Matemática) - Universidade Estadual do Centro-Oeste, Guarapuava, 2016.

JÚNIOR, A. G. M.; ESPÍRITO SANTO, A. O. A modelagem como caminho para "fazer matemática" na sala de aula. In: Congresso Norte/Nordeste de Educação em Ciências e Matemática, 7., 2006, Belém. Anais... Belém, 2006. p. 1-12.

KACZMAREK, D.; BURAK, D. Uma reflexão sobre as discussões curriculares e o uso da modelagem matemática em sala de aula. Boletim do LABEM, Niterói, v. 8, n. 14, p. 57-67, 2017.

KAISER, G. (Eds.), Mathematikunterricht im Spannungsfeld von Evolution und Evaluation. Festband für Werner Blum. Hildesheim: Franzbecker, 99-108, 2005.

KAVIATKOVSKI, M. A. C. A Modelagem Matemática como metodologia de ensino e aprendizagem nos anos iniciais do ensino fundamental. 2012. Dissertação (Mestrado em Educação) - Universidade Estadual de Ponta Grossa, Ponta Grossa, 2012.

KFOURI, W. Explorar e investigar para aprender matemática por meio da Modelagem Matemática. 2008. Dissertação (Mestrado Profissional em Ensino de Matemática) - Pontifícia Universidade Católica de São Paulo, São Paulo, 2008.

KISTEMANN, M. A. Resenha: Modelagem em Educação Matemática. Belo Horizonte: Autêntica. Bolema. Boletim de Educação Matemática,Rio Claro, v. 42B, p. 745, 2012.

KLÜBER, T. E. Formação de professores em Modelagem Matemática na Educação brasileira: questões emergentes. Educere et Educare, v. 12, n. 24, 2017.

KLÜBER, T. E. Modelagem Matemática: revisitando aspectos que justificam a sua utilização no ensino. In: BRANDT, C.F.; BURAK, D.; KLÚBER, T. E. (Org.). Modelagem Matemática: perspectivas, experiências e reflexões. 2 ed. Ponta Grossa, PR: EDUEPG, 2016, v. 1, p. 41-58.

KLÜBER, T. E. Uma metacompreensão da Modelagem Matemática na Educação Matemática. 396 f. 2012. Tese (Doutorado em Educação Científica e Tecnológica) - Universidade Federal de Santa Catarina. Florianópolis. 2012.

KLÜBER, T. E.; MUTTI, G.S. L.; TAMBARUSSI, C. M.; MARTINS, S. R. Prática pedagógica em artigos sobre formação de professores em modelagem: algumas considerações. In: Encontro Nacional de Educação Matemática, 2016, São Paulo. Educação Matemática na Contemporaneidade: desafios e possibilidades, 2016. v. XII. p. 1-12.

KLÜBER, T. E; BURAK, D. Modelagem Matemática: pontos que justificam a sua utilização no ensino. In: Encontro Nacional de Educação Matemática, 9, 2007, Belo Horizonte. Anais... Belo Horizonte: UNI-BH, 2007, p 1-19.

KLÜBER, T.E. Uma metacompreensão da Modelagem Matemática na Educação Matemática. 396 f, 2012. Tese (Doutorado em Educação Científica e Tecnológica) - Centro de Ciências Físicas e Matemática, Universidade Federal de Santa Catarina, UFSC, Florianópolis, 2012.

KOMAR, M. F. C. A Modelagem Matemática no processo de ensino e aprendizagem da matemática no ensino fundamental: ações e interações. 2017. Dissertação (Mestrado profissional em Ensino de Ciências Naturais e Matemática) - Universidade Estadual do Centro-Oeste, Guarapuava, 2017. 
KOVALSKI, L. Modelagem Matemática: articulações entre a prática e propostas curriculares oficiais. 2016. Dissertação (Mestrado em Matemática) - Universidade Estadual de Ponta Grossa, Ponta Grossa, 2016.

LEI $\beta$, D. Teacher intervention versus self-regulated learning? Teaching mathematics and its applications, England, v. 24, n. 2-3, p. 75-89, 2005.

LI, M. et al. A Study on Differences of High School Students' Mathematical Modeling Cognition. Journal of Mathematics Education, California, v. 7, n. 1, p. 1-15, jun. 2014.

LOPES, M. M. Um estudo sobre a modelagem matemática na educação básica. 2016.Trabalho de conclusão de curso (Graduação em Licenciatura em Matemática) - Faculdade de Engenharia de Guaratinguetá, Universidade Estadual Paulista “Júlio de Mesquita Filho”, Guarantiguetá, 2016. LUNA, A. V. A. A Modelagem Matemática na Formação Continuada e a recontextualização pedagógica desse ambiente em salas de aula. 184 f. 2012. Tese (Doutorado em Educação Científica e Formação de Professores) - Universidade Federal da Bahia, Salvador, 2012.

LUNA, A. V. A. A modelagem matemática na formação continuada e a recontextualização pedagógica desse ambiente em salas de aula. 184 f. 2012. Tese (Doutorado em Ensino, Filosofia e História das Ciências) - Universidade Federal da Bahia e Universidade Estadual de Feira de Santana, Salvador, 2012.

MARTENS, A. S. Formação continuada em modelagem matemática em contexto de pesquisa: um estudo a partir dos professores participantes. 2018. Dissertação (Mestrado em Educação) Universidade Estadual do Oeste do Paraná, Cascavel, 2018.

MARTINS, S. R. Formação continuada de professores em modelagem matemática na educação matemática: o sentido que os participantes atribuem ao grupo. 2016. Dissertação (Mestrado em Ensino) - Universidade Estadual do Oeste do Paraná, Foz do Iguaçu, 2016.

MATOS, C. A. P. Modelagem Matemática na EJA. Trabalho de Conclusão de Curso (Especialização em Educação na Diversidade e Cidadania com Ênfase em EJA/2014-2015) Faculdade de Educação, Universidade de Brasília, Brasília, 2015.

MATOS, D. V. A formação do professor que ensina matemática nos anos iniciais: uma análise dos conhecimentos legitimados pelo MEC e sua operacionalização na prática. 2017. Dissertação

(Mestrado em Educação em Ciências e Matemática) - Pontifícia Universidade Católica do Rio Grande do Sul, Porto Alegre, 2017.

MATOS, G. M. F.; SANTOS, M. L. A modelagem matemática como estratégia de ensino para aulas de Matemática no Ensino Médio. In: MIRANDA, S. C.: FERREIRA, J. R. R. F; SANTOS, M. L. (Org.). A educação profissional na sociedade do conhecimento e seus reflexos no Ensino de Ciências. 1. ed. Goiânia: Kelps, 2018, p. 187-210.

MATTÉ, I. Modelagem matemática e sensores de temperatura em uma escola técnica do Rio Grande do Sul. 2013. 160f. Dissertação (Mestrado em Ensino de Matemática) - Universidade Federal do Rio Grande do Sul, Porto Alegre, 2013.

MERLEAU-PONTY, M. Sinais. Tradução Fernando Gil. Lisboa: Editora Minotauro, 1962. MRAYYAN, S. How to Develop Teachers' Mathematical Molding Teaching Skills. Journal of Education and Practice, Hong Kong, v. 7, n. 12, p. 119-123, 2016.

MUTTI, G. de S. L. Práticas pedagógicas de professores da educação matemática num contexto de formação continuada em modelagem matemática na educação matemática. 2016. $236 \mathrm{f}$.

Dissertação (Mestrado em Ensino) - Universidade Estadual do Oeste do Paraná, Foz do Iguaçu, 2016. 
MUTTI, G. DE S. L.; KLÜBER, T. E. Aspectos que constituem práticas pedagógicas e a formação de professores em modelagem matemática. Alexandria (UFSC), v. 11, p. 85-107, 2018.

MUTTI, G. de S. L.; KLÜBER, T. E. Aspectos que constituem práticas pedagógicas e a formação de professores em modelagem matemática. Alexandria: Revista de Educação em Ciência e Tecnologia, Florianópolis, v. 11, n. 2, p. 85-107, nov. 2018. ISSN 1982-5153.

NETO, L. D. A. Modelagem Matemática no Ensino de Funções Polinomiais do $2^{\circ}$ Grau. XIII Jornada de Educação Matemática, Universidade Estadual de Goiás. Anais... 2010, p. 1-12.

OLIVEIRA, W. P. Modelagem matemática nas licenciaturas em matemática das universidades estaduais do Paraná. 2016. Dissertação (Mestrado em Educação) - Universidade Estadual do Oeste do Paraná, Cascavel, 2016.

PARANÁ. Diretrizes curriculares da educação básica: matemática. Secretaria de Estado da Educação. Secretaria de Estado da Educação. Departamento de Ensino de Primeiro Grau. Curitiba: SEED, 2008.

PAULO, R. M.; AMARAL, C. L. C.; SANTIAGO, R. A. A pesquisa na perspectiva fenomenológica: explicitando uma possibilidade de compreensão do ser-professor de matemática. Revista Brasileira de Pesquisa em Educação em Ciências, São Paulo, v. 10, n. 3, p. 71-86, 2010.

PEREZ, J. F; PAULO, R. M. Modelagem Matemática: Possibilidades Para Um Trabalho Em Sala De Aula. Sumaré-Revista Acadêmica Eletrônica, Sumaré, v. 12, n. 2, p. 2-16 2015.

PONTES, H. M. S. Modelagem matemática sob a ótica da Teoria dos Registros de Representação Semiótica e da educação dialógica. 2018. Tese (Doutorado em Educação) - Universidade Estadual de Ponta Grossa, Ponta Grossa, 2018.

QUARTIERI, M. T. A Modelagem Matemática na escola básica: a mobilização do interesse do aluno e o privilegiamento da matemática escolar. 281 f. 2012. Tese (Doutorado em Educação) Universidade do Vale do Rio dos Sinos, São Leopoldo, 2012.

RICOEUR, P. Interpretação e Ideologias. Rio de Janeiro: Editora F. Alves, 2011.

RICOEUR, P. Teoria da interpretação: O discurso e o excesso de significação. Lisboa: Editora Vozes, 2015.

ROSA, C. C. A Formação do Professor Reflexivo no Contexto da Modelagem Matemática. 265 f. 2013. Tese (Doutorado em Educação para Ciência e Matemática) - Universidade Estadual de Maringá, Maringá, 2013.

ROSA, M.; OREY, D. C. A modelagem como um ambiente de aprendizagem para a conversão do conhecimento matemático. Bolema, Rio Claro, v. 26, n. 42A, p. 261-290, abr. 2012. Disponível em: http://www.scielo.br/pdf/bolema/v26n42a/12.pdf. Acesso em: 13 nov. 2012.

ROSSO, A. J. Prefácio. O diálogo necessário do contexto histórico e cultural com a lógica na Modelagem Matemática, p.6-15. In: BRANDT, C. F.; BURAK, D.; KLÜBER, T. E. (Orgs.)

Modelagem Matemática: perspectivas, experiências, reflexões e teorizações. 2 ed. rev. ampl. Ponta Grossa, Editora UEPG, 2016.

SANTOS, L. R. Modelagem matemática: contribuições para a formação inicial de professores de matemática. 2012. Dissertação (Mestrado em Ensino de Matemática) - Universidade Franciscana, Santa Maria, 2012. 
SCHELLER, M. Modelagem Matemática na iniciação científica: contribuições para o ensino médio técnico. 2009. Dissertação (Mestrado Profissionalizante em Ensino de Matemática) - Universidade Federal do Rio Grande do Sul, Porto Alegre, 2009.

SCHONARDIE, B. Modelagem Matemática e introdução da função afim no ensino fundamental. 2011. Dissertação (Mestrado em Ensino de Matemática) - Universidade Federal do Rio Grande do Sul, Porto Alegre, 2011.

SETTI, E. J. K.; VERTUAN, R. E. A concepção de um Produto Educacional: do desenvolvimento de atividades em sala de aula à construção de um Blog de Modelagem Matemática. Revista BoEM, Florianópolis, v. 6, n. 10, p. 21-39, 2018.

SILVA, A. A. S; BICUDO, M. A. V. Análise de descrições de vivências em situações de constituição de conhecimento. In: BRANDÃO, C.; CARVALHO, J. L.; RIBEIRO, L.; COSTA, A. P. (orgs.). A prática na Investigação Qualitativa: exemplos de estudos. Aveiro: Ludomedia, 2018, p. 153-178. v. 2.

SILVA, J. F. O uso das TICs no ensino superior e suas contribuições para a educação estatística. 2014. 115 f. Dissertação (Mestrado em Ensino de Ciências) - Universidade Cruzeiro do Sul, São Paulo, 2014.

SILVA, J. M. A; LIMA, C. R. O; LIRA, D. A. N. Uma abordagem interdisciplinar no processo de ensino: aproximando saberes da matemática e da física. In: SEMINÁRIO NACIONAL DO ENSINO MÉDIO - SENACEM, 5., 2018, Mossoró. Anais... Mossoró: editora, 2018. p. 183-190.

SILVA, M. M; SILVA, V. S; ROSA, C. C. Modelagem matemática: uma alternativa pedagógica. In: XIII Encontro Sul-Mato-Grossense de Educação Matemática. Anais... Ponta Porã - Mato Grosso do Sul, p. 364-373, 2017.

SILVA, M. N. Modelagem matemática na formação continuada: análise das concepções de professores em um curso de especialização. 2009. Dissertação (Mestrado em Educação) - Pontifícia Universidade Católica de São Paulo, São Paulo, 2009.

SILVA, M. V. Concepções prévias de professores e formação continuada em modelagem matemática. 2017. Dissertação (Mestrado em Educação) - Universidade Estadual do Oeste do Paraná, Cascavel, 2017.

SILVA, S. C.; LOBEIRO, A. M.; MACOWSKI, K. H.; CORREA, W. J. Modelagem Matemática na Engenharia Ambiental: motivação à aprendizagem significativa. Revista NUPEM, Campo Mourão, v. 4, n. 7, p.93-106, ago./dez. 2012.

SILVA, V. S. Modelagem Matemática na formação inicial de pedagogos. $212 \mathrm{f}, 018$. Tese (Doutorado em Educação) - Universidade Estadual de Ponta Grossa, Ponta Grossa, 2018.

SILVEIRA, E. Modelagem matemática em educação no Brasil: entendendo o universo de teses e dissertações. 208 f. 2007. Dissertação (Mestrado em Educação) - Universidade Federal do Paraná, Curitiba, 2007.

SILVEIRA, E. Modelagem matemática em educação no Brasil: entendendo o universo de teses e dissertações, 208 f, 2007. Dissertação (Mestrado em Educação) - Universidade Federal do Paraná, Curitiba, 2007.

SKOVSMOSE, O. Cenários de investigação. Bolema, Rio Claro, v. 13, n. 14, p. 66-91, 2000.

SOISTAK, A. V. Uma experiência com a Modelagem Matemática no Ensino Médio Profissionalizante. In: BRANDT, C. F.; BURAK, D.; KLÜBER, T. E. (orgs.). Modelagem 
matemática: perspectivas, experiências, reflexões e teorizações. 2. ed. Ponta Grossa: Editora UEPG, 2016, p. 107-130.

SOISTAK, A. V. F. Modelagem matemática no contexto do ensino médio: possibilidade de relação da matemática com o cotidiano. 2006. Dissertação (Mestrado em Educação) - Universidade Estadual de Ponta Grossa, Ponta Grossa, 2006.

SONEGO, G. V. As contribuições da etnomodelagem matemática no estudo da geometria espacial. 2009. Dissertação (Mestrado em Ensino de Matemática) - Universidade Franciscana, Santa Maria, 2009.

SONEGO, G. V.; BISOGNIN, E. Explorando a Geometria Espacial por meio da Etnomodelagem Matemática. VIDYA, Santa Maria, v. 30, n. 2, p. 14, 2010.

SOUZA, E. G.; LUNA, A. V. A. Modelagem Matemática nos Anos Iniciais: pesquisas, práticas e formação de professores. Revemat, Florianópolis, v. 9, p. 57-73, 2014.

SOUZA, K. J. Formação inicial do professor de matemática: a pesquisa no estágio curricular supervisionado. In: X Encontro Nacional de Educação Matemática Educação Matemática, Cultura e Diversidade Salvador - BA. Anais..., p. 1-10, 2010.

SOUZA, R. A. A modelagem matemática como proposta de ensino e aprendizagem do conceito de função. 2011. Dissertação (Mestrado em Educação) - Pontifícia Universidade Católica de São Paulo, São Paulo, 2011.

STEIN, E. Aproximações sobre Hermenêutica. Porto Alegre: EDIPUCRS, 2010.

TAMBARUSSI, C. M. A formação de professores em modelagem matemática: considerações a partir de professores egressos do programa de desenvolvimento educacional do Paraná - PDE. 2015. Dissertação (Mestrado em Educação) - Universidade Estadual do Oeste do Paraná, Cascavel, 2015.

TATSCH, K. J. S. A aprendizagem de conteúdos de funções e estatística por meio da modelagem matemática: alimentação, questões sobre obesidade e desnutrição. 2006. Dissertação (Mestrado em Ensino de Matemática) - Universidade Franciscana, Santa Maria, 2006.

TATSCH, K. S.; BISOGNIN, V. Modelagem matemática no Ensino Médio: alimentação, obesidade e desnutrição. Vidya, Santa Maria, v. 1, p. 163-180, 2007.

TEODORO, F. P. A recontextualização da Modelagem Matemática na prática pedagógica nos anos iniciais. 2018. Dissertação (Mestrado em Educação para a Ciência e a Matemática) Universidade Estadual de Maringá, Maringá, 2018.

WIDJAJA, W. Building awareness of mathematical modelling in teacher education: A case study in Indonesia. In: STILLMAN, G. A. KAISER, G., BLUM, W.; BROWN, J. (orgs.). Teaching mathematical modelling: connecting to research and practice, international perspectives on the teaching and learning of mathematical modelling. Dordrecht: Springer, 2013. p. 583-593.

ZUKAUSKAS, N. S. T. Modelação matemática no ensino fundamental: motivação dos estudantes em aprender geometria. 2012. Dissertação (Mestrado em Educação em Ciências e Matemática) Faculdade de Física, Pontifícia Universidade Católica do Rio Grande do Sul, Porto Alegre, 2012. 